\title{
Urdimento
}

Revista de Estudos em Artes Cênicas

E-ISSN: 2358.6958

\section{OCDE e Educação Teatral}

Entrevista com: Andreas Schleicher, Stéphan Vincent-Lancrin, Ellen Winner, Thalia Goldstein concedida à André Luiz Lopes Magela

\section{Para citar este artigo:}

MAGELA, André Luiz Lopes. OCDE e Educação Teatral. Entrevista com: Andreas Schleicher, Stéphan VincentLancrin, Ellen Winner, Thalia Goldstein. Urdimento, Florianópolis, v. 3, n. 39, nov./dez. 2020.

DOI: http:/dx.doi.org/10.5965/14145731033920200501 


\title{
OCDE e Educação Teatral
}

Entrevista com: Andreas Schleicher, Stéphan Vincent-Lancrin, Ellen Winner, Thalia Goldstein concedida à André Luiz Lopes Magela ${ }^{1}$

\begin{abstract}
Resumo
Entrevista realizada por escrito em maio de 2020 com Andreas Schleicher, diretor de educação da OCDE - Organização para a Cooperação e Desenvolvimento Econômico, enfocando questões educacionais que direta ou indiretamente dizem respeito à educação teatral. Foram também entrevistados Stéphan Vincent-Lancrin, Ellen Winner e Thalia Goldstein, autores de Livro da OCDE dedicado ao ensino de artes em escolas. Os assuntos abordados giraram em torno da importância da educação artística, conexões da educação artística com competências, políticas públicas em educação e agenda econômica mundial. A entrevista é precedida por uma apresentação de autoria do entrevistador.
\end{abstract}

Palavras-chave: OCDE. PISA. Educação teatral. Políticas educacionais. Andreas Schleicher.

\section{OECD and Theatre Education}

\begin{abstract}
Written interview in May 2020 with Andreas Schleicher, director of education at the OECD - Organization for Economic Cooperation and Development, focusing on educational issues that directly or indirectly concern theatre education. The interview was also addressed to Stéphan Vincent-Lancrin, Ellen Winner and Thalia Goldstein, authors of an OECD book dedicated to teaching arts in schools. The approached topics comprehended the importance of artistic education, connections of artistic education with competencies, public policies in education and the global economic agenda. The interview is preceded by a preamble authored by the interviewer.
\end{abstract}

Keywords: OECD. PISA. Theatre education. Education policies. Andreas Schleicher. 


\section{OCDE y Educación Teatral}

\section{Resumen}

Entrevista escrita, producida en mayo de 2020 con Andreas Schleicher, director de educación de la OCDE - Organización para la Cooperación y el Desarrollo Económicos, centrada en cuestiones educativas que directa o indirectamente se refieren a la educación teatral. Algunas de las preguntas también fueron dirigidas a Stéphan Vincent-Lancrin, Ellen Winner y Thalia Goldstein, autores de un libro de la OCDE dedicado a la educación artística en las escuelas. Los temas comprendieron la importancia de la educación artística, conexiones entre la educación artística con competencias y políticas de educación pública relacionadas con la agenda económica mundial. La entrevista es precedida por un preámbulo escrito por el entrevistador.

Palabras clave: OCDE. PISA. Educación teatral. Políticas educativas. Andreas Schleicher. 


\section{Urdimento}

Apresentação

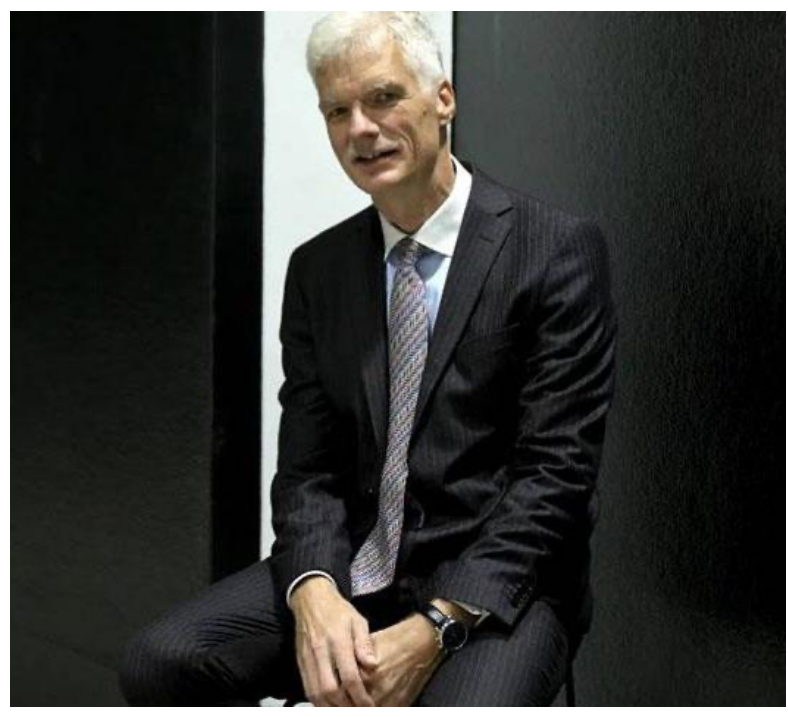

Andreas Schleicher ${ }^{2}$

Meu interesse por Andreas Schleicher surgiu quando tomei conhecimento de uma afirmação proferida por ele na House of Commons (Câmara dos Deputados), na Inglaterra, em fevereiro de 2019. Schleicher havia sido convidado para falar sobre os desafios da educação diante das mudanças tecnológicas e, em determinado momento, falou categoricamente para os parlamentares britânicos "na quarta revolução industrial, a arte pode se tornar mais importante do que matemática” (Reino Unido, 2019).

Por conta dessa frase tão peculiar, e aparentemente tão promissora para o campo da educação artística, comecei a investigar intensamente seu trabalho³. Porque quem estava afirmando isto não era um profissional da educação artística, mas alguém encarregado de organizar informações sobre a educação dirigidas ao desenvolvimento econômico. E alguém que é ouvido; muito ouvido.

Fonte: https://www.prisa.com/pt/noticias/noticias-1/andreas-schleicher-responde-a-las-preguntas-deprofesores-alumnos-y-familias. Andreas Schleicher nasceu na Alemanha e tem formação em física e matemática. É diretor do Directorate of Education and Skills da OCDE e coordena o PISA.

${ }^{3}$ Questões tratadas em artigo recente de minha autoria, "Recusa e adesão: resistência entre estudos da cognição e a educação teatral”, submetido para publicação. 


\section{Urdimento}

Andreas Schleicher é o diretor de Educação e Competências da OCDE Organização para a Cooperação e Desenvolvimento Econômico, organização internacional que promove, entre outras iniciativas, o PISA - Programa de Avaliação Internacional de Estudantes (o teste mundial para a educação). Esta diretoria é responsável por muitas publicações sobre educação em geral e algumas que, direta ou indiretamente, afetam a educação artística. Schleicher é autor de vários livros baseados nos dados produzidos pelas ações da OCDE.

Nesses vinte anos de aplicação do PISA, talvez possamos traçar uma linha de mudanças na qual, no início, a ideia de "educação em primeiro lugar" era vista como algo exagerado. Hoje, essa ideia parece ter sido mais aceita em alguns países, mesmo que ainda não tenha sido colocada em prática de forma suficientemente abrangente. A frase de Schleicher no parlamento inglês sobre a arte sugere que talvez possamos pensar num tempo em que seja factível a ideia de uma priorização à educação artística.

No contato com a bibliografia sobre educação da OCDE e com as muitas entrevistas que Schleicher concedeu, percebo uma oportunidade para ser construído um momento em que as aulas de artes tenham uma participação maior e efetivamente importante nas dimensões sociais ligadas àquilo que é considerado essencial - até mesmo a sobrevivência. Esta foi minha motivação inicial para propor esta entrevista.

Também percebo uma flagrante lacuna de informação sobre a OCDE em nosso meio acadêmico. Fui surpreendido, nos últimos meses, com a pergunta "o que é a OCDE?” vinda de muitos de meus colegas e de pessoas ligadas à educação. Havendo aderência ou resistência a ideias e políticas promovidas pela OCDE e outros órgãos desta esfera de ação mundial, friso ser inequívoca e urgente a necessidade de conhecer estas influências, que não são nada pequenas, sobre a educação no mundo e no Brasil. Sobre este assunto, recomendo literaturas críticas às ações da OCDE ou consideradas similares: (Pereira, 2019), (Biesta, 2018), (Laval, 2019), (Ydesen, 2019). Não acho aqui necessário recomendar literaturas específicas a favor destas políticas, uma vez que já recomendo (e fortemente) a consulta ao 
material da própria $\mathrm{OCDE}^{4}$, com especial atenção ao livro mais recente do próprio Schleicher (2018), disponível também em português.

Há outros elementos no âmbito aqui enfocado que considero relevantes para a educação teatral. As ideias propostas por Schleicher parecem contemplar visões mais contemporâneas e pertinentes de educação (a meu ver, condizentes com autores como Gilles Deleuze e Félix Guattari), onde enxergamos o mundo não em termos de objetos previamente definidos, mas como redes de relações, como movimento e articulações complexas de forças e formas (o que podemos chamar de "abordagem intensiva"). Um exemplo seria a perda de espaço do ensino de história como exposição de datas e fatos históricos para uma compreensão consistente de forças sociais que constroem a história. Ou se propomos que o ensino de teatro em escolas não diz respeito tanto ao teatro já instituído e executado por profissionais, mas à teatralidade (e/ou performatividade) em um sentido mais amplo, a uma relação teatral com a vida. Citando uma afirmação de Schleicher, a ideia de que aprender matemática não consiste em fixação de fórmulas, mas sim pensar matematicamente em todas as esferas da vida (enredos teatrais são matemáticos - por exemplo, na constituição de causalidades, verossimilhanças e organização de prioridades entre eventos).

Do mesmo modo, vejo, neste corpus de escritos e falas sobre a educação, mesmo que sejam bastante atreladas às forças econômicas vigentes, a oportunidade de fazermos valer, na educação teatral, as tendências conceituais mais recentes afeitas à chamada cognição corporificada, Embodied Cognition (Lakoff, 1987) (Johnson, 1987) (Varela, Rosch, Thompson, 2003). Nesta forma de lidar com os campos de estudos associados à cognição humana, há um questionamento das visões tradicionais sobre as relações entre corpo, cérebro e mente. Além disso, estas concepções operam quase uma fusão dos aspectos nomeados como racionais e emocionais. Conseguir que estas perspectivas sejam tomadas em conta talvez contribua para o estabelecimento da importância de que estas aulas ampliam o pensamento teatral dos alunos - que é, de modo complexo, (em termos "antigos", obsoletos até) racional, cognitivo, mental, corporal, 
emocional.

Neste aspecto, devemos prestar atenção à ênfase, presente em falas de Schleicher e em muitos materiais da OCDE, para o que eles chamam, dentre outros termos, de competências emocionais, sociais e interpessoais ${ }^{5}$. Andreas Schleicher fez notar, em um discurso há doze anos, que "essas habilidades raramente são levadas em conta nas decisões de admissão" e, em outras ocasiões, que essas formas de cognição não são facilmente traduzíveis em números ${ }^{6}$. Mas atualmente, mesmo que de um modo ainda incipiente, este conjunto de elementos não é mais considerado como uma mera base ou dimensão de fundo; algo que é apenas notado quando está em falta ou causando problemas. Ou um substrato cuja posse ou domínio é necessária apenas para assegurar-se das competências que sempre importaram: aquelas associadas de modo superficial e imediato aos empregos.

Hoje, há uma maior visibilidade para estas chamadas habilidades interpessoais; e talvez todo esse campo seja, em algum momento, o principal objetivo do trabalho pedagógico no ensino básico e nos processos de avaliação educacional. O livro de 2015 da OCDE sobre habilidades sociais e emocionais é um movimento nesse sentido, em termos de inclusão, nos pensamentos sobre as medidas dos resultados educacionais e aprimoramento das estratégias pedagógicas, de elementos complexos que antes não podiam ser medidos.

De todo modo, o mercado já vem absorvendo este domínio. No ano passado, por exemplo, a IBM publicou um relatório abordando o que considerou como habilidades necessárias para pessoas que lidam com dispositivos que usam Inteligência Artificial. Ratificando outras notícias e previsões, o relatório indica que a importância destas chamadas habilidades comportamentais está cada vez mais em evidência.

Isso ainda não é sistematicamente trabalhado, mas esses elementos (por

${ }^{5}$ Apesar de reconhecer vantagens nestes materiais da OCDE, eu não adoto e até critico este tipo de categorização.

${ }^{6}$ PISA trabalha essencialmente com estatísticas (seu principal instrumento de persuasão). Daí a preocupação em converter fenômenos em números. 


\section{Urdimento}

OCDE e Educação Teatral

exemplo, perspectivação, agência, autorregulação, trabalho em equipe, cooperação, flexibilidade) podem ser considerados como presentes em uma prática pedagógica de teatro. A recente promoção da criatividade e sua relação com aulas de teatro configura um exemplo de ação neste sentido.

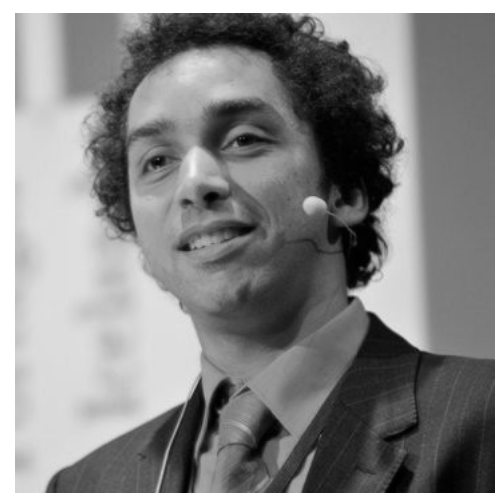

Stéphan Vincent-Lancrin?

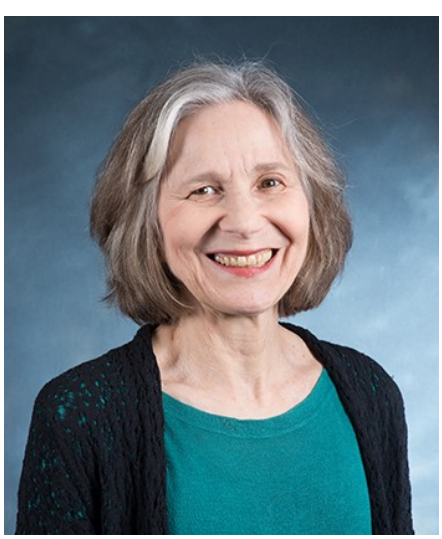

Ellen Winner ${ }^{8}$

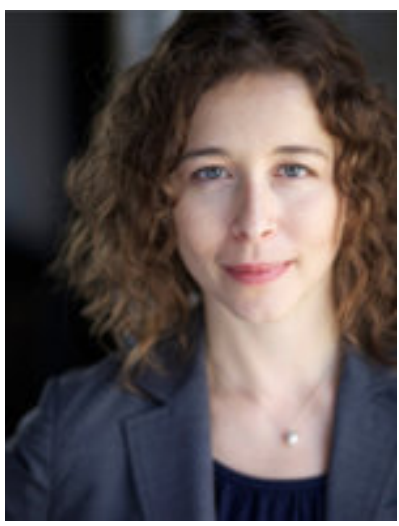

Thalia Goldstein ${ }^{9}$

${ }^{7}$ Analista sênior do centro de pesquisa e inovação educacional (CERI) da OCDE. Doutor em economia e mestre em administração de negócios e filosofia. Fonte: https://fr.linkedin.com/in/stephan-vincent-lancrin

${ }^{8}$ Psicóloga, professora no Boston College, especialista em psicologia da arte. Colaborou no Project Zero, da Universidade de Harvard, projeto que desde 1967 realiza pesquisas sobre artes e cognição. Fonte: https://www.bc.edu/bc-web/schools/mcas/departments/psychology/people/faculty-directory/ellenwinner.html

${ }^{9}$ Professora de psicologia do desenvolvimento aplicada na George Mason University - EUA. Seu trabalho é focado em como competências sociais e emocionais em crianças se conectam com o engajamento em jogos de faz-de-conta, teatro, drama, e outras atividades de imaginação. Vários de seus artigos estão disponíveis para download em https://www.researchgate.net/profile/Thalia_Goldstein/research . Fonte: https://www.researchgate.net/profile/Thalia_Goldstein 
Por isto, convidei, além de Schleicher, outras pessoas envolvidas em publicações da OCDE, Ellen Winner, Thalia Goldstein e Stéphan Vincent-Lancrin ${ }^{10}$, a quem foram dirigidas perguntas mais específicas. Thalia Goldstein aproveitou a oportunidade para recomendar artigos de sua autoria que conectam competências interpessoais, tomada de perspectiva e autorregulação com aulas de teatro, bem como um livro sobre pedagogias baseadas em ensino de teatro (disponíveis para download $\left.{ }^{11}\right)^{12}$.

Tentei abordar ao máximo as questões éticas e políticas que intrinsecamente permeiam a associação entre educação e desenvolvimento econômico.

Podemos encontrar, no material educacional da OCDE, uma opção explícita em diminuir a influência da intuição e dos pressupostos e a importância de tomar decisões baseadas em evidências estatísticas - os dados levantados pelo PISA. O lema é medir e examinar o que já funcionou bem - decisões e estratégias correlacionadas ou que causaram experiências bem sucedidas. Mas ao mesmo tempo, as publicações da OCDE e observações verbais de Schleicher extrapolam isso, compondo um conjunto de pensamentos e ideias sobre educação que, em última análise, estabelece diretrizes e recomendações sobre o que fazer para melhorar os resultados de cada país em testes de educação. De certa forma, isso afirma uma posição, um corpo filosófico de ações sobre educação, articulado em "fundamentos teóricos e conceituais", como já disse Schleicher.

O livro da OCDE sobre habilidades para 2030 apresenta uma visão muito ampla sobre a educação nos últimos 200 anos, abordando, de forma crítica, questões políticas e formas de pensar hegemônicas associadas à produção e ao capitalismo. A maior parte das recomendações presentes no livro recentemente publicado de Schleicher (2018) sobre o PISA (educação para todos, acolher e fomentar diferenças e dedicar mais tempo e atenção aos estudantes que estão em dificuldades, por exemplo) são bem afinadas com a ideia de um Estado de

${ }^{10}$ Estes três autores produziram o livro Arts for art sake, pela OCDE, em 2013.

${ }^{11}$ https://www.researchgate.net/profile/Thalia_Goldstein/research

${ }^{12}$ Me permito sugerir também uma referência francesa sobre este tópico: estudos de Marie-Christine Bordeaux sobre pesquisas que tentam avaliar efeitos da educação artística e cultural na França. (Bordeaux, 2016). 
bem estar social e de controle rigoroso e eficaz do capitalismo predatório. Pontos essenciais sobre a desigualdade são muito controversos no imaginário político, econômico e social das pessoas...

Na esteira deste último tópico, o ético, muitas análises da OCDE se detêm sobre como criar condições para que professores e alunos tenham mais motivação para enfrentar os desafios da educação (com especial atenção a todos aqueles que têm dificuldades nesse processo). Podemos citar algumas referências, presentes no livro de Schleicher: alocar os profissionais com melhores resultados para escolas cujos alunos apresentam mais dificuldades; a não separação entre alunos com dificuldades e aqueles com boas notas; a importância de valorizar o professor e seu trabalho colaborativo. Mais dedicadamente, temos o livro de 2017 da OCDE sobre "bem-estar do aluno", no qual são abordadas "atitudes, disposição, estratégias mentais, habilidade para lidar com a vida”. Podemos, de forma audaciosa, associar uma expressão presente nas obras de Schleicher e da OCDE, "traduzir intenções em ações", com o conceito de agenciamento, central à filosofia de Gilles Deleuze e Félix Guattari, e fortemente ligado à nossa capacidade de estabelecer vínculos pertinentes e potentes com a vida. Aparentemente em grande afinidade com isso, Alain de Botton (2019), para citar um exemplo com outro tipo de abordagem, defende a centralidade de uma Educação Emocional nos sistemas educacionais.

Numa verticalização deste tema, as perguntas finais a Schleicher remetem à formação continuada e sua consequente exigência de que os professores administrem conflitos entre a abertura ao novo e a fidelidade ao que é importante a ser mantido; avaliar o que serve e deve ser conservado contra o que pode e/ou deve ser mudado ou extinto. Alunos e professores precisam de uma forte capacidade de adaptação se pretendem atender às demandas dinâmicas do mundo econômico (ou ao menos sobreviver a elas...). E neste processo é necessária grande atenção sobre quais práticas e valores devem ser preservados, por exemplo, algumas tradições culturais e valores sociais mais profundos - os éticos e aqueles que dão sentido à vida.

Mas a abordagem da educação tendo como foco (ou objetivo) a agenda 
econômica implica na articulação bem conflituosa entre responsabilidade social e interesses imediatos e autocentrados de agentes que detêm mais poder econômico. O que está em jogo, e sob ameaça, são objetivos coletivos mais abrangentes e os valores e necessidades mais constitutivos das sociedades. Poucos fatores impedem que a atitude de saudável vigilância e aprendizagem constante caia no fetiche de inovação e na depreciação de importantes características culturais dos envolvidos nestes processos.

Por fim, e retomando o motivo inicial de propor esta entrevista, a finalidade principal aqui não é apregoar pontos positivos do material aqui citado como razões para a ele aderir. O intento é que seja aproveitado este caráter, extraído destes materiais da OCDE, de comprometimento social e valorização da dimensão artística. Esta perspectiva talvez contribua para pressionar os atores sociais que têm poder de decisão sobre a educação, para que adotem mais medidas promotoras de um bem estar social abrangente, no nosso caso, naquilo que concerne à educação teatral.

A argumentação vislumbrada é que nosso posicionamento não é ideologizado (como tem sido mais do que nunca atacado), mas que o trabalho em educação teatral pode contribuir, também, para reivindicações associadas ao desenvolvimento econômico. Esta entrevista visa colaborar com informações que possam alimentar esta forma de resistência, incentivando professores e outros profissionais da educação a pesquisar mais estes materiais que têm sido utilizados como determinantes para a educação.

\section{A Entrevista}

Seria possível pensarmos em um momento futuro onde a ideia de 'educação artística em primeiro lugar' poderia estar disseminada mundialmente? Já haveria vislumbres ou esboços de como isso poderia ser incentivado ou implementado? Como é sua percepção do acolhimento, por parte de profissionais da educação e estudantes do mundo, dessa visão de que as artes são mais importantes na educação do que o senso comum considera?

Andreas Schleicher - Bem, hoje em dia, a educação não é mais apenas sobre ensinar algo aos alunos, mas sobre ajudá-los a desenvolver uma bússola confiável 
e ferramentas para navegar com confiança através de um mundo cada vez mais complexo, volátil e incerto. Sucesso na educação hoje diz respeito a identidade, é sobre agência e é sobre propósito. Trata-se de criar curiosidade - abrir mentes, compaixão - abrir corações, e é sobre coragem, mobilizando nossos recursos cognitivos, sociais e emocionais para agir. E essa também será nossa melhor arma contra as maiores ameaças de nossos tempos: ignorância - a mente fechada, o ódio - o coração fechado e o medo - o inimigo da agência. Tudo isso mostra por que as artes se tornaram tão centrais para a educação.

Vivemos neste mundo em que o tipo de coisas que são fáceis de ensinar e testar também se tornaram fáceis de digitalizar e automatizar. O futuro diz respeito a parear a inteligência artificial dos computadores com os valores e as habilidades cognitivas, sociais e emocionais dos seres humanos. Será nossa imaginação, nossa consciência ${ }^{13}$ e nosso senso de responsabilidade que nos permitirá aproveitar a tecnologia para moldar o mundo para melhor.

A questão essencial é que, se queremos ficar à frente do nosso tempo, temos que encontrar e refinar as qualidades que são únicas para nossa humanidade, e que não competem, mas sim complementam, as capacidades que criamos em nossos computadores. As escolas precisam desenvolver humanos de primeira classe, não robôs de segunda classe. A educação fez grandes avanços para nos ajudar a entender o mundo ao nosso redor e até mesmo explorar planetas distantes. Está na hora de a educação nos ajudar a entender melhor nossas próprias mentes e experiências. E é melhor entendermos nossas mentes, antes que algum algoritmo tome decisões por nós ${ }^{14}$.

Tudo isso trouxe a arte e a educação artística da periferia para o centro da educação. E as artes abrem portas para outros campos de conhecimento também.

Ellen Wainer - Eu não sou nem um pouco otimista quanto a educação artística vir a ser considerada mais importante do que todas as outras matérias.

${ }^{13}$ No original, awareness, que é mais amplo do que "consciência", englobando também algo como "atenção ampliada".

${ }^{14}$ No original - And we better understand our minds before some algorithm will make our minds up for us. 
Mas eu certamente acredito que venha a ser TÃO importante. Não penso que tenha havido muita mudança na percepção dos profissionais da educação sobre isso. As artes ainda são vistas como algo extra.

Esta é uma questão pessoal especialmente dirigida a Andreas Schleicher: você estudou em uma escola Waldorf, na Alemanha, por um período significativo de sua vida. Qual foi a influência dessa pedagogia na forma como você percebe o ensino de artes? O ensino de teatro na Alemanha, com sua theatrepädagogik, ou a ideia de bildung, também influenciaram sua trajetória? Você poderia sugerir ou comentar sobre outras influências no mundo que poderiam contribuir para fomentar, no imaginário das pessoas, uma maior consideração sobre as artes na educação?

Andreas Schleicher - Sim, a escola Waldorf desempenhou um papel importante para que eu experimentasse e reconhecesse o valor das artes. Mas também tive a sorte de tocar em uma orquestra juvenil com um maestro que foi um dos educadores mais incríveis que já conheci. Ele nos ensinou a ouvir, a nos tornarmos conscientes, a nos vermos fazer parte de algo maior, valorizar a perfeição e praticar com diligência e persistência não apenas na escola, mas também em casa. E talvez o mais importante, a música me ensinou a amar aprender. E mais tarde viajei pelo mundo com a orquestra e talvez por isso me interessei em trabalhar internacionalmente. E finalmente acabei me tornando um bom aluno.

E isso é muito mais do que uma experiência pessoal. Um corpo crescente de pesquisas mostra como as habilidades nas artes se relacionam estreitamente com outras importantes capacidades humanas. Por exemplo, tem sido demonstrado empiricamente que a educação musical fortalece o desempenho acadêmico, a decodificação de palavras e as habilidades fonológicas e há evidências de que a educação musical pode facilitar a aprendizagem de línguas estrangeiras.

A educação teatral, por exemplo por meio da encenação de histórias em sala de aula, tem se mostrado como benéfica para as habilidades verbais, e os alunos que estudam as artes visuais são mais fortes no raciocínio geométrico do que os alunos que não estudam as artes visuais. E estudos mostraram que o treinamento em dança melhora as habilidades visuoespaciais. 
E mesmo que a educação artística não contribua para nenhum resultado acadêmico, ela ainda deve ter um lugar importante em nossas escolas, simplesmente pela importância da arte como experiência humana. Qualquer um de nós teria dificuldades em imaginar uma vida boa sem as artes e alguma consciência cultural.

Claro, estar a par da importância da educação artística é uma coisa, mas projetar e oferecer educação artística inovadora e eficaz é outra coisa. As artes podem ser ensinadas de uma forma que melhore as qualidades humanas, ou podem ser ensinadas de um modo pobre. O que quero dizer é que, por mais importante que seja o currículo, precisamos entender melhor as pedagogias e atitudes que levem a melhores resultados.

Há uma ênfase no PISA para a ideia de que os testes não sejam direcionados ao conhecimento que o aluno possui, mas àquilo que ele pode fazer com o que sabe. Isso parece ser bastante pragmático, em um contexto com excesso de informações e fácil acesso a elas, mas onde o que realmente importa é a relação que o aluno estabelece com esses dados. Ao mesmo tempo, se afina a concepções mais contemporâneas de aprendizagem, como algo da ordem do processual - o processo que é construído junto ao aluno.

Levando isso em conta, como você percebe a compreensão e a adesão, por professores, alunos e outros atores sociais da educação, dessa perspectiva de conteúdo educacional como algo da ordem do operacional, do intensivo, do relacional, e não como mera informação?

Andreas Schleicher - É claro que o conhecimento de última geração sempre permanecerá importante. Pessoas inovadoras ou criativas geralmente têm competências especializadas em um campo de conhecimento ou uma prática. Por mais importante que seja aprender a aprender, sempre aprendemos por aprender alguma coisa. Mas o sucesso na educação não é mais calcado sobre a reprodução do conhecimento de conteúdo; ele tem a ver com extrapolar o que sabemos e aplicar esse conhecimento criativamente em situações novas. A compreensão epistêmica - por exemplo, pensar como um cientista, filósofo ou matemático está prevalecendo sobre conhecer fórmulas, nomes ou lugares específicos. Da mesma forma, a história não se trata principalmente de lembrar datas, nomes e lugares, mas de ser capaz de pensar como um historiador, ou seja, entender como 
a narrativa de uma sociedade surgiu, se desenvolveu, avançou e às vezes se desmantelou quando o contexto muda. Portanto, a educação hoje precisa ser muito mais sobre formas de pensar (envolvendo criatividade, pensamento crítico, resolução de problemas e capacidade de julgar), formas de trabalho (incluindo comunicação e colaboração), ferramentas para trabalhar (incluindo a capacidade de reconhecer e explorar o potencial de novas tecnologias) e sobre a capacidade de viver em um mundo multifacetado como cidadãos ativos e responsáveis.

A abordagem convencional na escola trata frequentemente de dividir problemas em partes e pedaços administráveis e, em seguida, ensinar os alunos a como resolver esses pedaços. Mas as sociedades modernas criam valor sintetizando diferentes campos do conhecimento, fazendo conexões entre ideias que antes não pareciam relacionadas. Isso requer estar familiarizado e receptivo ao conhecimento em outras áreas.

Nas escolas de hoje, os alunos normalmente aprendem individualmente e, no final do ano letivo, certificamos suas conquistas individuais. Mas quanto mais interdependente o mundo se torna, mais precisamos de grandes colaboradores e orquestradores. A inovação hoje é raramente o produto de indivíduos trabalhando isoladamente, mas sim um resultado de como mobilizamos, compartilhamos e integramos conhecimento. O bem-estar das sociedades depende cada vez mais da capacidade das pessoas de adotar ações coletivas. As escolas, portanto, precisam se tornar melhores em ajudar os alunos a aprender a desenvolver uma consciência do pluralismo da vida moderna. Isso significa ensinar e recompensar a colaboração na mesma medida que a realização acadêmica individual, fomentando que os alunos tanto pensem por si mesmos, como ajam com e para os outros.

De maneira articulada com o incentivo presente nos trabalhos do PISA a se basear decisões educacionais em evidências, há todo um corpo de recomendações explícitas e implícitas nas obras escritas e entrevistas que derivam dele. Inevitavelmente, estas análises e recomendações se associam a um posicionamento ético. De fato, existe um forte direcionamento, neste material, aos componentes éticos e relativos às esferas pessoais dos envolvidos na educação. Dar uma relevância central à esfera ética também é, inevitavelmente, assumir uma posição. Compor ou adotar uma filosofia ou sistema de ideias - uma ideologia, alguns 
diriam.

Como foram esses processos de emergência dessa percepção (a importância da dimensão ética), de assumir essa posição e tecer um discurso e uma linha de ações para validá-la? Até que ponto e de que forma você vê a questão ética na educação e no futuro profissional dos alunos como 'técnica', como um pragmatismo (para ensinar cooperação, por exemplo)? Essa dimensão pode ser traduzível em termos objetivos ou mensuráveis?

Andreas Schleicher - Esse parece ser o desafio mais difícil na educação moderna: como incorporar valores na educação. Os valores sempre foram centrais para a educação, mas é hora de passarem de aspirações implícitas para metas e práticas explícitas de educação de maneiras que ajudem as comunidades a mudar de valores situacionais - o que significa "faço tudo o que a situação me permite fazer" - para valores sustentáveis que geram confiança, laços sociais e esperança. Se a sociedade não construir fundações sob as pessoas, muitos tentarão construir muros, não importando o quão autodestrutivo isso seja.

Tentar limitar a educação à entrega de conhecimentos acadêmicos traz o risco de que a educação acabe emburrecendo as pessoas para competir com computadores, ao invés de focar em traços humanos fundamentais que permitirão que a educação fique à frente dos desenvolvimentos tecnológicos e sociais. Pergunte-se por que é muito mais fácil para as tecnologias digitais substituir os trabalhadores do conhecimento de hoje do que os caçadorescoletores de ontem. A resposta é que, na organização de trabalho taylorista e na especialização de habilidades humanas, perdemos muitas das capacidades humanas que podem não ter um valor diretamente instrumentalizável no trabalho.

Logo no primeiro parágrafo do documento OECD Learning Compass 2030, afirmase que a educação deve incentivar principalmente os alunos a "entender e apreciar diferentes perspectivas e visões de mundo, interagir respeitosamente com os outros e tomar medidas responsáveis em direção à sustentabilidade e ao bem-estar coletivo". Como tem sido sua percepção, ao longo do tempo e nas diferentes regiões do mundo, sobre a compreensão e aceitação de princípios como esses? E em situações em que são bem recebidas, quais foram as estratégias de implementação dessas ideias?

Andreas Schleicher - Cingapura foi o primeiro país que encontrei que coloca 
valores explicitamente no centro de sua estrutura curricular, enfatizando o respeito, a responsabilidade, a resiliência, a integridade, o cuidado e a harmonia na escola. Esses valores visam dar contornos às qualidades de caráter dos alunos, como consciência social e de si, gestão de relacionamento, autogestão e tomada de decisão responsável. Na verdade, essa estrutura refere-se às qualidades de caráter como "Valores em Ação".

Como um todo, a estrutura curricular de Cingapura foi projetada para o fomento de uma pessoa confiante, um aprendiz auto direcionado, um cidadão interessado e um cooperador ativo. As escolas de Cingapura usam esta estrutura para projetar programas curriculares e co-curriculares que ajudarão os alunos a desenvolver as competências requisitadas. Além disso, espera-se que todos os alunos participem de programas "Valores em Ação" que ajudem a construir um senso de responsabilidade social. Ainda assim, mesmo em Cingapura, muito disso continua sendo uma aspiração que é, na melhor das hipóteses, apenas parcialmente refletida na forma como os alunos realmente aprendem e os professores realmente ensinam.

Embora o contexto para criar e implementar um novo currículo do século XXI seja forte, parece haver uma confluência de fatores igualmente forte no caminho desta mudança. Pais que temem que seu filho não passe em um exame podem não confiar em qualquer abordagem que prometa alcançar mais com menos. Os professores e seus sindicatos podem se preocupar com o fato de que, se forem solicitados a ensinar material mais subjetivo, como habilidades sociais e emocionais, não serão mais avaliados apenas pelo que ensinam, mas também por quem são. Os administradores escolares e os formuladores de políticas podem sentir que não serão mais capazes de gerenciar escolas e sistemas escolares quando os parâmetros de medida para o sucesso mudarem de conhecimento de conteúdo facilmente quantificável para certas qualidades humanas que podem não se revelar plenamente até bem depois de seus alunos se formarem. Desenvolver respostas convincentes para essas preocupações exigirá uma abordagem corajosa direcionada para o projeto de currículos e avaliações modernas. Elaborar currículos escolares para a próxima geração que vão além da 
experiência passada exigirá, portanto, uma extraordinária liderança. Envolverá esclarecer e defender planos de estudo e avaliações que priorizem a profundidade da compreensão e estimulem, em toda a comunidade, a ampliação de engajamento na aprendizagem.

Há muitas dificuldades na medição e tratamento sistemático de habilidades interpessoais e emocionais e, se consideramos a ideia, afeita ao PISA, de que a avaliação é o primeiro passo para fazer algo melhor, ainda haveria muito a fazer nesse campo. Considerando isto, como é hoje esse processo de melhorar a precisão na abordagem desses elementos não rotineiros e interpessoais? Quais são as perspectivas neste campo?

Ellen Winner - Eu não sou uma especialista na avaliação de habilidades sociais e emocionais, mas certamente há novas medidas que foram desenvolvidas para este fim. Não posso falar sobre o quão precisos são, mas sou sempre cética de que uma medição por auto relato seja uma boa medida. É melhor que professores, pais e colegas classifiquem o mesmo estudante.

Se considerarmos essas competências "soft", e a existência de habilidades diretamente ligadas às artes em geral e às habilidades teatrais (operando na vida cotidiana, isto deve estar claro), pergunto: existe ou poderia haver alguma maneira de incluir no PISA algumas formas de avaliação que não sejam pela escrita? Algo corporal, por exemplo? Dinâmica de grupo?

Ellen Winner - É uma ideia interessante. Embora eu suspeite que seria difícil avaliar isto de uma forma confiável.

O livro da OCDE de 2013 Art for Art's Sake? The Impact of Arts Education, de sua autoria, trata das aulas de artes adotando, como abordagem central, a transferência de habilidades (por exemplo, aulas de artes ajudando com os resultados da linguagem e matemática $)^{15}$. Você conhece ou vislumbra outras formas de medir e fomentar habilidades artísticas e teatrais, formas autônomas que vejam essas habilidades como um fim em si mesmas dentro do contexto da educação?

${ }^{15}$ Nota do entrevistador: Como veremos abaixo, minha pergunta não foi bem formulada. Como a entrevista foi escrita (o que dificulta a reversibilidade no diálogo), preferi manter essa imprecisão e colar aqui uma breve síntese do livro, extraída do site da OCDE: "A educação artística é muitas vezes dita como um meio de desenvolver o pensamento crítico e criativo. Este relatório examina a situação do conhecimento empírico sobre o impacto da educação artística nesses tipos de resultados." 
Ellen Winner - Certamente podemos avaliar o aprendizado em uma forma artística. Isso é muito mais fácil de fazer do que tentar demonstrar transferência - que é notoriamente difícil de demonstrar.

Stéphan Vincent-Lancrin - O livro argumenta que as aulas de artes devem ser realizadas principalmente para fomentar habilidades nas artes e que a maneira adequada de medir seu sucesso é se elas cumprem esse objetivo. No entanto, há um interesse também sobre a contribuição das artes para outros assuntos ou para outros tipos de habilidades, como criatividade e pensamento crítico. Mostramos como estava a pesquisa sobre isso e que tipo de resultados foram encontrados por fortes projetos de pesquisa. É surpreendente que tanta pesquisa sobre educação artística se concentre nessa questão de transferência, e tão pouco nos resultados artísticos. Mesmo na criatividade, um assunto que a maioria dos educadores de artes sente que tem muito a contribuir, há pouca pesquisa - e, na verdade, muito pouco para concluir qualquer coisa. A educação teatral de fato teve um dos resultados mais fortes, na medida em que claramente permitiu a aquisição de habilidades verbais quando textos foram encenados em sala de aula.

Em nosso trabalho que acompanhou o fomento e avaliação da criatividade e do pensamento crítico $^{16}$ (Vincent-Lancrin et. al., 2020), trabalhamos sobre a educação STEM ${ }^{17}$ e na educação artística, e desenvolvemos testes específicos de realização em música e artes visuais (com a dificuldade adicional de que eles eram internacionais e não podiam ser sobre a cultura artística). Isso mostra que a educação artística pode ser medida e avaliada através das lentes do desenvolvimento de habilidades artísticas. Não trabalhamos educação teatral, e talvez tivesse sido mais difícil de fazer, mas não tentamos, de todo modo. Basicamente, o que tentamos fazer nessas duas áreas foi ver quanto conhecimento os alunos tinham de vocabulário técnico, o quanto podiam ver ou aprender, até que ponto podiam ver ou ouvir as emoções que eram (a princípio) expressas por peças de música ou artes visuais, e o que eles sabiam sobre isso

${ }^{16}$ Listado nas referências ao final.

${ }^{17}$ Grupo de disciplinas que engloba Ciências, Tecnologia, Engenharia e Matemática. 
como uma forma de arte em geral. Fizemos duas versões, uma para o ensino fundamental e outra para alunos do ensino médio.

Thalia Goldstein - Eu não penso que nosso livro faça isso ${ }^{18}$. Na verdade, construímos o argumento oposto - o de que as aulas de artes NÃO devem ser adotadas simplesmente porque ajudam os resultados da linguagem e da matemática. Em vez disso, as aulas de artes devem ser incluídas na educação para seu próprio interesse como partes de uma educação cultural e plena. Sua ajuda para outros domínios não artísticos é incidental à principal razão pela qual elas devem ser incluídas na educação, e é fundamental tanto reconhecer esse fato quanto estimar de modo correto (nem demais nem de menos) as pesquisas sobre o que as artes realmente fazem para campos não artísticos. As habilidades artísticas e teatrais têm sido medidas por muito tempo dentro das próprias formas de educação artística, embora não de modo formalizado em um contexto psicológico. Os professores são a melhor fonte aqui, pois há muito tempo têm que fornecer notas e medir as habilidades aprendidas nessas salas de aula. $O$ conselho educacional mais recente nos Estados Unidos, o Every Student Succeeds Act, inclui o Common Core Arts Standards ${ }^{19}$ (mas não estou envolvida nisso).

Existem ações ou planos específicos da OCDE que abordem ou fomentem a educação artística ou teatral na educação mundial? Você tem conhecimento de iniciativas onde elementos diretamente ligados ao teatro estão relacionados com as chamadas habilidades comportamentais? ${ }^{20}$

Stéphan Vincent-Lancrin - No livro Art for art's sake, existem alguns estudos usando o teatro contra o comportamento antissocial. Houve também evidências

18 Nota do entrevistador: Como eu já mencionei em nota anexa a esta pergunta, acredito que minha questão foi formulada de uma forma que gerou esse conflito, provavelmente porque eu citei apenas a matemática e a língua materna como exemplos. O fato de que meus quadros epistemológicos, baseados na filosofia intensiva de Gilles Deleuze, são diferentes dos adotados nesses estudos também causa isso, creio eu. Mas este não é um assunto a ser abordado aqui, uma vez que eu já elaborei essa abordagem em outros artigos meus.

19 https://www.nationalartsstandards.org/

20 Como complemento a essa resposta, conferir os artigos de Thalia Goldstein, listados nas referências bibliográficas. 
iniciais de que a educação teatral desenvolveu, junto aos alunos, a empatia e a tomada de perspectiva. Pode-se imaginar que ela também desenvolve uma melhor regulação emocional, em parte porque faz você melhor avaliar e entender como expressar as emoções - e assim, o que as desencadeia, etc. Além disso, muitos coaches em comunicação vêm do teatro, pois existem algumas técnicas importantes que podem ser transferidas no mundo profissional, por exemplo, quando as pessoas fazem apresentações. Finalmente, como qualquer arte viva, há uma dimensão do medo do palco que força você a controlar suas emoções quando você se apresenta. Acho que você aprende com isso também.

\begin{abstract}
Muitas análises da OCDE concernem a incentivar professores e alunos a terem mais motivação para a educação. Você poderia mencionar algo, em algumas estratégias e políticas de alguns países, sobre componentes de terapia ou pelo menos algum cuidado para um desenvolvimento pessoal mais amplo ou holístico em ações de educação?
\end{abstract}

Ellen Winner - As crianças tendem a ser mais motivadas e engajadas em aulas de artes do que outras disciplinas, pois outras matérias são frequentemente ensinadas de forma não prática, onde os alunos se sentam passivamente e ouvem. Outras matérias deveriam tomar emprestado o método de estúdio das artes ${ }^{21}$ para envolver as crianças na realização de projetos durante o tempo de aula, enquanto o professor circula para consultas individuais. Isso provavelmente aumentaria a motivação e o engajamento dos alunos.

Stéphan Vincent-Lancrin - Um dos aspectos importantes da educação artística é que ela funciona de forma diferente das outras. Em parte, porque ela se tornou uma matéria de baixo comprometimento, onde as apostas são baixas para os alunos. Muitas vezes é até vista como um momento recreativo para descontrair, após os assuntos mais "importantes", pelo menos no sentido de determinar a carreira acadêmica e profissional da maioria dos alunos. Mas, em

${ }^{21}$ De certo modo, um ambiente similar a um ateliê ou laboratório de teatro, onde coletivamente os alunos, orientados pelo professor, realizam um projeto. Talvez possamos dizer que o ensino por projetos se afina a esta ideia. 
parte, é só porque as disciplinas artísticas tendem a funcionar de forma diferente com os alunos - para o melhor. Eles dão feedback individualizado, desafiam os alunos, fazem-nos trabalhar em suas emoções e ir além delas, fazem com que eles experimentem o estado de fluxo, fazendo-os trabalhar em coisas que eles gostam mas que são desafiadoras, etc. Foi o que colegas mostraram em seu livro Studio Thinking, sobre educação em artes visuais (Hetland et. al, 2007). Em muitos aspectos, a força da educação artística não deve ser encontrada na forma como ela se transfere para outros domínios, mas como ela fornece um método para um melhor ensino e aprendizagem. Mas há má educação artística também. $E$ isso traz à minha mente dois filmes franceses com algumas cenas sobre educação artística: uma bela relação entre alunos e seu professor de teatro em Gang of four de Rivettes (La bande des quatre); um primeiro relacionamento muito bom tornando-se azedo em Games of Love and Chance de Abdel Kechiche (L'esquive), quando a professora fica decepcionada com seu aluno e apenas o abandona. Como todos que passaram por isso sabem, a educação artística também pode ser cruel e elitista, e encontrar o nível certo de desafio e engajamento para os alunos continua sendo uma de suas dificuldades, como é o caso de qualquer experiência educacional.

$\mathrm{Na}$ esfera individual, como você vê a articulação entre preparar o aluno para o mundo econômico e, ao mesmo tempo, muitas vezes em contradição com isso, para sua capacidade de autodeterminação, na qual as pessoas fazem o que pensam como sendo o melhor, de forma coerente com sua proposta ético-estética de vida?

Andreas Schleicher - Eu não penso que essa tensão não exista mais no mundo de hoje. Sim, você quer contratar um engenheiro competente, mas um engenheiro competente no mundo de hoje é um engenheiro ético. Novamente, na era da inteligência artificial, precisaremos pensar mais sobre como educar humanos de primeira classe. A tecnologia e a inteligência artificial não são poderes mágicos, são apenas amplificadores e aceleradores extraordinários que acrescentam velocidade e precisão. A IA ampliará boas ideias e boas práticas da mesma forma que amplifica más ideias e más práticas. A IA é eticamente neutra, mas está sempre nas mãos de pessoas que não são neutras. A única razão pela 
qual devemos temer os robôs é porque eles sempre nos obedecerão e nunca se rebelarão.

A realidade é que os alunos ficam a maior parte do tempo atrás de mesas individuais e há pouco tempo para aprendizado colaborativo. Isso ficou claro - e de modo surpreendente - nos resultados da primeira avaliação do PISA das habilidades colaborativas para resolução de problemas, em 2015. Em média, entre os países da OCDE, menos de um em cada dez estudantes de 15 anos poderia completar tarefas de resolução de problemas que exigiam que eles prestassem atenção à dinâmica de grupo, tomassem medidas para superar obstáculos e resolver desacordos com outros, mesmo quando o conteúdo dessas tarefas era relativamente simples.

De forma mais geral, as mudanças nas exigências de habilidades elevaram o papel das competências sociais e emocionais. Tais habilidades estão envolvidas em alcançar metas, conviver e trabalhar com os outros e na gestão das emoções. Elas incluem qualidades de caráter como perseverança, empatia ou tomada de perspectiva, atenção plena, ética, coragem e liderança. Na verdade, desenvolver esse tipo de características foi o que distinguiu muitas das escolas de elite que visitei. Mas para a maioria dos alunos, a formação de caráter na escola continua sendo uma questão de sorte, dependente de ser uma prioridade para seu professor, uma vez que há muito poucos sistemas de ensino que fizeram de metas tão amplas uma parte essencial do que eles esperam dos alunos.

Habilidades sociais e emocionais, por sua vez, se imbricam com a diversidade de formas importantes. Elas podem ajudar os alunos a viver e trabalhar em um mundo no qual a maioria das pessoas precisa apreciar uma gama de ideias, perspectivas e valores, e colaborar com pessoas de diferentes origens culturais, muitas vezes aproximando espaço e tempo através da tecnologia; e um mundo em que suas vidas serão afetadas por questões que transcendem as fronteiras nacionais. A comunicação eficaz e o comportamento apropriado dentro de diversas equipes também são chaves para o sucesso em muitos trabalhos, e permanecerão assim à medida que a tecnologia continua a tornar mais fácil para as pessoas se conectarem em todo o mundo. Os empregadores buscam cada vez 
mais atrair alunos que se adaptam facilmente e são capazes de aplicar e transferir suas habilidades e conhecimentos para novos contextos. A prontidão para o trabalho em um mundo interconectado exige que os jovens entendam a complexa dinâmica da globalização e estejam abertos a pessoas de diferentes origens culturais.

Envolver-se com diferentes perspectivas e visões de mundo exige que os indivíduos examinem as origens e implicações dos outros e suas próprias suposições. Isso, por sua vez, implica um profundo respeito e interesse por quem o outro é, seu conceito de realidade e suas perspectivas. Reconhecer a posição ou crença de outro não é necessariamente aceitar essa posição ou crença. No entanto, a capacidade de ver através de múltiplas lentes oferece oportunidades para aprofundar e questionar suas próprias perspectivas e tomar decisões mais maduras. Onde não temos sucesso com isso, estamos construindo nossos sistemas de educação na areia. A questão primordial é que podemos tentar demarcar fronteiras, mas não podemos sustentá-las em face da realidade da interdependência.

\section{Referências}

BIESTA, Gert. Interrupting the politics of learning. In: ILLERIS, Knud. Learning Theorists... In Their Own Words. New York: Routledge, 2018.

BORDEAUX, Marie-Christine (coordinatrice générale). L'évaluation des "effets » de l'éducation artistique et culturelle - Étude méthodologique et épistémologique (rapport finale). GRESEC - Université Grenoble Alpes / ECP - Université Lyon 2, août, 2016. Disponível em: https://recherche.univ-lyon2.fr/ecp/ressources/axe3/levaluation-des-effets-de-L2019education-artistique-et-culturelle-etudemethodologique-et-epistemologique/view

BOTTON, Alain de. The School of Life: An Emotional Education. London: Hamish Hamilton, 2019.

DAWSON, Katie, KIGER LEE, Bridget. Drama-based Pedagogy - activating learning across the curriculum. Bristol (England): Intellect Books, 2018. 
HETLAND, Lois, WINNER, Ellen, VEENEMA, Shirley, SHERIDAN, Kimberly. Studio Thinking: The Real Benefits of Visual Arts Education. New York: Teachers College Press (Columbia University), 2007.

JOHNSON, Mark. The body in the mind - the bodily basis of meaning, imagination, and reasoning. Chicago: The University of Chicago Press, 1987.

LAKOFF, George. Women, fire, and dangerous things - what categories reveal about the mind. Chicago: The University of Chicago Press, 1987.

LAVAL, Christian. A escola não é uma empresa - o neoliberalismo em ataque ao ensino público. São Paulo: Boitempo, 2019.

OCDE (OECD). OECD Future of Education and Skills 2030. OECD Learning Compass 2030 - A Series of Concept Notes. Paris: OECD Publishing, 2019. Disponível em: http://www.oecd.org/education/2030-project/teaching-andlearning/learning/learning-compass-

2030/OECD_Learning_Compass_2030_Concept_Note_Series.pdf

OCDE (OECD). Students' Well-Being. PISA 2015 Results (Volume III). Paris: PISA, OECD Publishing, 2017. http://dx.doi.org/10.1787/9789264273856-en

OCDE (OECD). Skills for social progress: the power of social and emotional skills. Paris: OECD skills Studies, OECD Publishing, 2015. Disponível em: https://www.oecd.org/education/skills-for-social-progress-9789264226159en.htm

PEREIRA, Rodrigo da Silva. Proposições da OCDE para América Latina: o PISA como instrumento de padronização da educação. In: RIAEE - Revista IberoAmericana de Estudos em Educação, v. 14, n. esp. 3, p. 1717-1732, out., 2019. Disponível em: https://periodicos.fclar.unesp.br/iberoamericana/article/view/12756

REINO UNIDO. Oral evidence: Fourth Industrial Revolution. Witness: Andreas Schleicher. Tuesday 26 February 2019. House of Commons, 2019. Disponível em: http://data.parliament.uk/writtenevidence/committeeevidence.svc/evidencedocu ment/education-committee/fourth-industrial-revolution/oral/97393.html

SCHLEICHER, Andreas. Primeira Classe: como construir uma escola de qualidade para o século XXI. Paris: OECD Publishing, 2018. Disponível em: https://www.oecd.org/publications/primeira-classe-7475e4e1-pt.htm

VARELA, Francisco, ROSCH, Eleanor, THOMPSON, Evan. A mente incorporada ciências cognitivas e experiência humana. Porto Alegre: Artmed, 2003.

VINCENT-LANCRIN, Stéphan, GONZÁLEZ-SANCHO, Carlos, BOUCKAERT, Mathias, DE LUCA, Federico, FERNÁNDEZ-BARRERA, Meritxell, JACOTIN, Gwénaël, Joaquin Urgel, VIDAL, Quentin. Desenvolvimento da Criatividade e do Pensamento Crítico dos Estudantes - O que significa na escola. São Paulo: Fundação Santillana, 2020. 
Disponível em https://fundacaosantillana.org.br/2020/03/05/desenvolvimentoda-criatividade-e-do-pensamento-critico-dos-estudantes/

WINNER, Ellen, GOLDSTEIN, Thalia, VINCENT-LANCRIN, Stéphan. Art for Art's sake?: the impact of arts education. Paris: Educational Research and Innovation, OECD Publishing, 2013. http://dx.doi.org/10.1787/9789264180789-en . Versão resumida em espanhol disponivel em: https://www.oecd.org/education/ceri/ES_ARTS_overview_V5_print.pdf

YDESEN, Christian (Editor). The OECD's historical rise in education - The formation of a global governing complex. Cham (Switzerland): Palgrave Macmillan, 2019.

Recebido em: 19/06/2020

Aprovado em: 31/08/2020 


\section{Urdimento}

OCDE e Educação Teatral

Urdimento - Revista de Estudos em Artes Cênicas Urdimento.ceart@udesc.br 